\title{
Price of the Digital Nomad Culture for Employer, Employee
}

\author{
Muhamad Sayuti Mansor*
}

The term 'Work from Home' (WFH) came to prominence in the aftermath of the COVID-19 pandemic. Working from home appears to be the most practical way of curbing the spread of the virus, with repeated enforcements of the Movement Control Order (MCO). Despite the fact that WFH has become the "new normal", it is worth noting that this phenomenon is far from new; it used to be standard practice across human civilisation.

In France, for example, there were more than 1.5 million home-based employees in the 1900s according to one census. The same can be said of Malaya during those times, when a majority of the population were farmers, craftsmen, and small-scale merchants who worked out of their homes or shop houses. Rapid shifts in this pattern occurred only with the development of industrial culture when newly set up factories and mega business outlets led to a significant influx of employees into major cities. These employees had to adhere to fixed working hours, standardised labour wages, and daily commutes to and from their workplaces.

Despite the lack of flexibility associated with office-based work, employees today have a greater sense of privacy, with a clear distinction between their public work obligations and personal life. To put it another way, if you work in a factory, you know when the day is over and you can be completely at home during off-hours. In this regard, the decline of home-based work translates into more privacy and pleasure in one's private life. In tune with the notion that "the only constant in life is change", however, we now find ourselves at a crossroads once again in modern times. The swift advancement of science and technology has made a work-from-home lifestyle feasible.

The digital nomad lifestyle is now gaining currency worldwide. The COVID-19 pandemic was really just a small push to change our conventional way of working from a designated workspace, known as the office. What began as a preventive measure to limit the spread of the virus is now a viable option, with many businesses opting for WFH mode or a mix. WFH is unlikely to end in the near future, given our current situation. Rather, it will likely be around for a long time.

Unfort unately, WFH comes at a cost. Although it provides greater flexibility and removes transportation hassles for employee, while also saving money on office maintenance, it comes at the expense of the employee's personal life. 
WFH implies that there is no boundary between living and working, as well as between a worker's personal life and his public duties. Flexible working hours, on the other hand, sometimes entail procrastination and finishing tasks in the wee hours. As a result, it's worth mentioning the irony that a person who works from home might also lose their home!

Moreover, WFH is a luxury that not everyone can afford. WFH might be a nightmare for less fortunate employees, especially those in lower-paying positions, because they do not have a suitable workspace at home. Some of them also live in overcrowded or cramped spaces.

To summarise, we must be mindful of the WFH culture. Employers must allow adequate time for their employees to adapt to these unexpected developments. More reasonable and effective supervision may be needed since disturbances to the typical workflow and pace are possible. Employers might also assist their underprivileged employees by offering home office appliances. Employees, on the other hand, must re-calibrate their attitude in order to adapt to this new environment. To achieve work-life balance, they should set aside some time for their personal life. Second, they must be realistic and avoid the trap of blaming themselves for minor setbacks in performance. Lastly, they must have a deep sense of amanah (trustworthiness) when carrying out their duties, especially when they are not closely supervised by their employer.

\section{Notes}

* Muhammad Sayuti Mansor is a Special Assistant to the Founding CEO cum Analyst at the International Institute of Advanced Islamic Studies (IAIS) Malaysia. He can be contacted at: sayuti@iais.org.my. 